\title{
Outpatient management of asthma in adults: A snapshot of the 2020 GINA report
}

\section{ABSTRACT}

The Global Strategy for Asthma Management and Prevention publishes an annual report on asthma management and prevention. The report reflects the most recent evidence on asthma and its treatment and provides recommendations for clinical practice. This article reviews the guidelines with a focus on what's new and clinically important for practitioners treating this patient population.

\section{KEY POINTS}

Adults with asthma should receive combination therapy with an inhaled corticosteroid and a long-acting betaagonist on an as-needed basis for mild asthma or regular daily use for moderate or severe asthma.

The recommended option is low-dose budesonide-formoterol, or beclomethasone-formoterol as an alternative.

Monotherapy with a short-acting beta-agonist on an as-needed basis is no longer recommended as the initial therapy for mild asthma.

The preferred agent for rescue therapy is as-needed low-dose inhaled corticosteroid/long-acting beta-agonist. sthma, as Defined by the Global Strategy for Asthma Management and Prevention (GINA), is a heterogeneous disease characterized by chronic airway inflammation. ${ }^{1}$ It is hallmarked by respiratory symptoms such as wheezing, shortness of breath, chest tightness, or cough that vary over time and in intensity, together with variable expiratory airflow limitation.

In adults, variable expiratory airflow limitation can be confirmed several ways:

- Postbronchodilator increase in forced expiratory volume in 1 second $\left(\mathrm{FEV}_{1}\right)$ by more than $12 \%$ and more than $200 \mathrm{~mL}$ from baseline 10 to 15 minutes after the patient takes 200 to $400 \mu \mathrm{g}$ of albuterol

- Average daily diurnal peak expiratory flow variability of more than $10 \%$

- $\mathrm{FEV}_{1}$ increase by more than $12 \%$ and more than $200 \mathrm{~mL}$ from baseline after 4 weeks of anti-inflammatory treatment outside of respiratory infections

- Fall in $\mathrm{FEV}_{1}$ of more than $10 \%$ and more than $200 \mathrm{~mL}$ from baseline with exercise

- Fall in $\mathrm{FEV}_{1}$ of $20 \%$ or more from baseline with standard bronchial challenge (methacholine or histamine), or a fall of $15 \%$ or more with standardized hyperventilation or hypertonic saline or mannitol challenge). ${ }^{1}$

Recognized clinical phenotypes include allergic asthma, nonallergic asthma, adult-onset (late-onset) asthma, asthma with persistent airflow limitation, and asthma with obesity. Asthma severity (mild, moderate, severe) is classified based on frequency of day and night 
symptoms, as well as on the level of stepwise treatment required to control symptoms and prevent exacerbations.

\section{CLINICAL SETTING}

The field of asthma has evolved significantly during the last several years. This review of the GINA 2019 update focuses on changes in the management of asthma in adult outpatients. We use the following abbreviations: short-acting beta-agonist (SABA), long-acting beta-agonist (LABA), inhaled corticosteroid (ICS), and oral corticosteroid (OCS).

\section{INTENDED AUDIENCE}

This review is intended for healthcare providers who manage adult patients with asthma in the outpatient setting.

\section{WHO WROTE THE GUIDELINES?}

The GINA Science Committee was established in 2002 and is composed of voluntary members who are leaders in both adult and childhood asthma research. The committee meets biannually with the American Thorac-

For off-label recommendations, the GINA committee urged professional judgment and consideration of existing local and national guidelines ic Society (ATS) and European Respiratory Society (ERS) to review the latest in asthma research in order to release new recommendations annually.

For these recommendations, a PubMed literature search covering approximately 18 months yielded 1,137 clinical trials or metaanalysis publications of which 906 were screened out for duplicates, relevance, or quality. Each of the remaining 231 publications was reviewed by at least 2 committee members for overall scientific impact. Of those, 123 were subsequently discussed in the biannual GINA Science Committee meetings in 2018 for consideration of inclusion in the annual guidelines.

Of note, any new therapy or indication required regulatory approval by at least 1 agency and at least 2 good-quality studies in suitable populations before committee recommendation. Off-label recommendations were made for existing therapies if the committee found suitable supportive evidence. For these off-label recommendations, the committee emphasized that clinicians should use their professional judgment and take into account existing local and national guidelines.

\section{WHAT ARE THE MAIN RECOMMENDATIONS?}

Monotherapy with SABA on an as-needed basis is no longer recommended as the initial therapy for mild asthma because it increases the risk of severe exacerbations and asthmarelated deaths. To decrease these risks, all adults with asthma should receive combination therapy with an ICS and an LABA on an as-needed basis for mild asthma or regular daily use for moderate or severe asthma. The recommended option is low-dose budesonideformoterol, or beclomethasone-formoterol as an alternative. If an SABA is used, it should be simultaneously combined with a low-dose ICS.

\section{WHAT IS DIFFERENT FROM PREVIOUS GUIDELINES?}

- The preferred agent for rescue therapy is as-needed low-dose ICS-LABA (preferably budesonide-formoterol); prior guidelines recommended SABA as needed for first-line therapy.

- Replacement of "upper airway dysfunction" and "vocal cord dysfunction" with "inducible laryngeal obstruction," and the replacement of "fixed airflow limitation" with "persistent airflow limitation."

- Emergency room or hospital discharge follow-up after severe exacerbations should occur within 2 days.

- New add-on therapies for step 5 treatments include low-dose daily azithromycin (off-label), dupilumab (anti-IL4 receptor antibody), and tiotropium, based on specific drug indications.

- Trial use of high-dose ICS-LABA for 3 to 6 months is now limited to use in step 5 treatment (previously recommended in steps 4 and 5) owing to increased risk of side effects; for similar reasons, maintenance OCS is no longer a preferred treatment in step 5.

- Of note, the GINA 2020 guidelines address asthma and COVID-19; they emphasize continuing to take all prescribed asthma medications, having a clearly writ- 
ten asthma action plan, and preferentially using metered-dose inhalers over nebulizers when possible.

\section{WHAT IS THE EXPECTED CLINICAL IMPACT?}

The expected clinical impact of the latest guidelines is a decreased incidence of severe asthma exacerbations and asthma-related deaths globally.

It should be noted that until 2017, ICSLABA combinations had a boxed warning from the US Food and Drug Administration (FDA) based on early LABA trials (Serevent Nationwide Surveillance study and the Salmeterol Multicenter Asthma Research trial) that showed increased risk of serious adverse asthma outcomes (death, hospitalization, intubation). 2,3

Due to these concerns, the FDA required manufacturer-conducted noninferiority postmarket safety trials for ICS-LABA combinations vs ICS alone. Four trials (3 adult and 1 pediatric) enrolling approximately 45,000 participants were conducted and examined fluticasone-salmeterol vs fluticasone, budesonide-formoterol vs budesonide, and mometasone-formoterol vs mometasone for efficacy and the aforementioned serious asthma outcomes.

In summary, these trials found that the ICS-LABA combinations were effective in reducing asthma exacerbations requiring corticosteroids and did not significantly increase the risk of serious adverse asthma outcomes. ${ }^{4-7}$ Despite the removal of the boxed warning, no ICS-LABA combination has an FDAapproved indication for treating acute bronchospasm on an as-needed basis, as the GINA 2019 guidelines recommended. ${ }^{8}$

\section{DO OTHER SOCIETIES AGREE OR DISAGREE?}

The annual GINA report is endorsed by the ATS and ERS. After the GINA 2019 report was published, ${ }^{8}$ the ATS and ERS published a joint guideline on the management of severe asthma in January 2020. ${ }^{9}$ Prior to this, their last independent publication was in 2014, which was also limited to the description of severe asthma. More recently, the National Heart Lung and Blood Institute (NHLBI) released updated guidelines in December 2020.10 Though the full review of the evidence behind those guidelines is beyond the scope of this article, a key difference in recommendations should be noted. The NHLBI 2020 guidelines still recommend as-needed SABA as the preferred initial treatment for intermittent asthma, with as-needed or daily low-dose ICS-LABA reserved for step 3. The American College of Chest Physicians has no published asthma guidelines.

\section{HOW WILL THIS CHANGE DAILY PRACTICE?}

Combination ICS-LABA should be considered for all patients with asthma, and for select patients with mild asthma this should be considered on an as-needed basis replacing SABA as the sole therapy. The consideration for this change should be based on shared decisionmaking with each patient. Providers should discuss the risks and benefits of sole SABA therapy with patients, while acknowledging that symptoms may have been well controlled without exacerbations for many years on the patient's current regimen. Continued provider and patient education is a key for populationlevel success of any new society recommendations.

\section{WHEN WOULD GUIDELINES NOT APPLY?}

Availability and affordability of ICS-LABA combinations may limit widespread adoption of these recommendations. In these cases, GINA recommends that low-dose ICS be used when SABA is used. Timing of FDA approval for any ICS-LABA combination for an as-needed indication may influence medication coverage practices and, ultimately, affordability.

\section{DISCLOSURES}

The authors report no relevant financial relationships which, in the context of their contributions, could be perceived as a potential conflict of interest.
The expected clinical impact of the guidelines is a global decrease in severe asthma exacerbations and asthmarelated deaths 


\section{GINA ASTHMA REPORT}

\section{REFERENCES}

1. Global Initiative for Asthma. Global Strategy for Asthma Management and Prevention, 2020. https://ginasthma.org/gina-reports/. Accessed June 14, 2021.

2. Castle W, Fuller R, Hall J, Palmer J. Serevent nationwide surveillance study: comparison of salmeterol with salbutamol in asthmatic patients who require regular bronchodilator treatment. BMJ 1993; 306(6884):1034-1037. doi:10.1136/bmj.306.6884.1034

3. Nelson HS, Weiss ST, Bleecker ER, Yancey SW, Dorinsky PM; SMART Study Group. The Salmeterol Multicenter Asthma Research Trial: a comparison of usual pharmacotherapy for asthma or usual pharmacotherapy plus salmeterol. Chest 2006; 129(1):15-26. doi:10.1378/chest.129.1.15 Erratum in: Chest 2006; 129(5):1393.

4. Stempel DA, Szefler SJ, Pedersen S, et al.; VESTRI Investigators. Safety of adding salmeterol to fluticasone propionate in children with asthma. N Engl J Med 2016; 375(9):840-849. doi:10.1056/NEJMoa1606356

5. Peters SP, Bleecker ER, Canonica GW, , et al. Serious asthma events with budesonide plus formoterol vs. budesonide alone. N Engl J Med 2016; 375(9):850-860. doi:10.1056/NEJMoa1511190

6. Weinstein CL, Ryan N, Shekar T, et al; SPIRO Investigators. Serious asthma events with mometasone furoate plus formoterol compared with mometasone furoate. J Allergy Clin Immunol 2019; 143(4):13951402. doi:10.1016/j.jaci.2018.10.065

7. Stempel DA, Raphiou IH, Kral KM, et al; AUSTRI Investigators. Serious asthma events with fluticasone plus salmeterol versus fluticasone alone. N Engl J Med 2016; 374(19):1822-1830. doi:10.1056/NEJMoa1511049

8. Global Initiative for Asthma. Global Strategy for Asthma Management and Prevention, 2019. https://ginasthma.org/wp-content/uploads/2019/06/GINA-2019-main-report-June-2019-wms.pdf. Accessed June 14, 2021.

9. Holguin F, Cardet JC, Chung KF, et al. Management of severe asthma: a European Respiratory Society/American Thoracic Society guideline. Eur Respir J 2020; 55(1):1900588. doi:10.1183/13993003.00588-2019

10. National Heart, Lung, and Blood Institute. Asthma Management guidelines: focused updates 2020. https://www.nhlbi.nih.gov/health-topics/ asthma-management-guidelines-2020-updates. Accessed June 14, 2021.

Address: Kavya Kommaraju, MD, Department of Internal Medicine, G10, Cleveland Clinic, 9500 Euclid Avenue, Cleveland, $\mathrm{OH} 44195$; kommark@ccf.org 